\title{
Analysis Procedures \\ For \\ Progressive Collapse of Buildings
}

by

H. S. Lew ${ }^{1}$

\begin{abstract}
This paper presents simple analytical approaches for evaluating progressive collapse potential of low- and mid-rise buildings that could be used in routine design by design professionals. Although nonlinear time history analysis would be more realistic in representing progressive collapse phenomenon, high fidelity structural models to represent nonlinear structural behavior are required to produce accurate results. In routine design of low- and mid-rise buildings, simple static procedures with appropriate acceptance criteria would be more suitable for evaluating progressive collapse potential.
\end{abstract}

KEYWORDS: analysis; buildings; collapse; failure; linear; nonlinear; progressive collapse; static procedures.

\section{INTRODUCTION}

In recent years, there has been heightened awareness among building owners and U.S. government agencies of collapse of buildings in a "progressive" manner. Because buildings that collapse in a progressive way could lead to a catastrophic event, a large number of deaths and injuries and loss of properties, many owners of high-rise buildings and government agencies are interested in evaluating the progressive potential of existing buildings and in designing new buildings to resist progressive collapse. The National Institute of Standards and Technology (NIST) is working with design professionals, researchers, building owners, building regulators, and building code and standard developing organizations to develop guidelines for analyzing buildings to resist progressive collapse.

Progressive collapse is defined as the spread of an initial failure from element to element, eventually resulting in the collapse of an entire structure or a disproportionately large part of it [ASCE 2002]. When local failure of primary structural members propagate to failure of adjoining members, progressive collapse will ensue unless adjoining structural members arrest further progression of failure. For example, if a column in a multi-story framed building is destroyed due to explosion, structural members above the failed column will sustain large displacements instantaneously, and also will fail unless the beams that are framed to the column develop a catenary response to arrest collapse of the floor area that was supported by the failed column.

Progressive collapse is a dynamic and nonlinear event, as it takes place in a very short time frame and structural members undergo nonlinear deformation before failure. To analyze rigorously progressive collapse potential of a structure, nonlinear dynamic analysis should be performed to account for energy dissipation, large inelastic deformations, materials yielding, cracking and fracture. However, the nonlinear dynamic analysis requires step-by-step integration which is very time consuming. Furthermore, because of the general lack of structural behavior data especially related to beam to column connections of both steel and

\footnotetext{
${ }^{1}$ Building and Fire Research Laboratory, National Institute of Standards and Technology, Gaithersburg, Maryland, U.S.A 20899-8611
} 
concrete, it is difficult to evaluate the results of the analysis. As a result of these reasons, nonlinear dynamic analysis is not used in routine design and analysis of low- and mid-rise buildings, which account for nearly 93 percent of buildings in the U.S.

For buildings of 10 stories or less in height with relatively simple layouts, both the U.S. General Services Administration [GSA 2003] and the Interagency Security Committee [ISC 2001] recommend the alternate load path method be used to assess the vulnerability of new and existing buildings to progressive collapse. This prescriptive method requires a check of the capability of the structural system to resist removal of a specific critical structural member. Analytical procedures that could be used for the alternate load method are presented in this paper.

\section{Analysis Procedures}

\subsection{Linear Static Analysis}

The response of a structure to redistributed loads following the sudden loss of a critical loadcarrying member is dynamic and nonlinear. However, as in seismic design, one simple approach is to use an equivalent static elastic analysis if buildings have relatively simple layouts and do not fall in the following categories:

a) Buildings that utilize a combination of frames and walls in the structural systems,

b) Buildings with vertical discontinuities in columns and walls, which utilize transfer girders,

c) Buildings that have a large variance in structural bay size,

d) Buildings that have plan irregularities, and

e) Buildings that have closely spaced columns, which can lead to uncertainty in the application of a simplified analysis.

A more sophisticated analysis, such as nonlinear dynamic analysis, is required for buildings that have the above structural characteristics, (a) through (e).
When performing a static analysis, the characteristic loads to be applied to the structure are:

$$
\text { Load }=2(D L+0.25 L L)
$$

where

$$
\begin{aligned}
& D L=\text { dead load } \\
& L L=\text { live load }
\end{aligned}
$$

For the load combination in Eq. 1, only 25 percent of the live load is used since the probability of that full live load being present during a progressive collapse event is small. An amplification factor of 2 is applied to the load combination to account for dynamic effects.

After the static analysis, a demand-capacity ratio $(D C R)$ is computed for each of the structural members in the building.

$$
D C R=\frac{Q_{U D}}{Q_{C E}}
$$

where

$$
\begin{aligned}
Q_{U D}= & \text { force (bending moment, axial force, } \\
& \text { shear force) determined in a component } \\
& \text { or connection from the analysis } \\
Q_{C E}= & \text { expected ultimate, unfactored capacity } \\
& \text { (bending moment, axial force, shear } \\
& \text { force) of the component or connection. }
\end{aligned}
$$

In the analysis, design material strength may be increased by a strength-increase factor to account for expected actual strength of materials. For reinforced concrete members, this factor could be taken as 1.5. For steel members this factor may vary from 1.05 to 1.10 , depending on types and age of steel.

Using the $D C R$ criteria, structural members and connections that have $D C R$ values greater than 2.0 are considered to be severely damaged or collapsed [GSA 2003]. In the case of shear forces, failure is imminent when the $D C R$ value exceeds 1.0.

Once the $D C R$ s have been computed, the extent of damage or collapse can be determined. GSA specifies that the maximum allowable area of 
collapse resulting from the instantaneous removal of an exterior column (or wall) shall be smaller of the following two areas: (1) the structural bay directly associated with the removed column or (2) $170 \mathrm{~m}^{2}\left(1830 \mathrm{ft}^{2}\right)$ at the floor level directly above the removed column. Similar limits are given areas based on the removal of an interior column.

An interim design guide for buildings to resist progressive collapse proposed by the Department of Defense [UFC 2004] also considers the characteristic loads for the equivalent static load analysis.

$$
\text { Load }=1.0 D L+0.5 L L+0.2 W L
$$

where

$W L=$ wind load per ASCE 7-02.

Equation 2 does not include the dynamic amplification factor but includes 20 percent of the wind load.

Instead of calculating the demand capacity ratio $D C R$, the Uniform Facility Criteria (UFC) requires iterative analyses for linear elastic static methods. For example, when a structural member that cannot sustain a constant moment, that member is removed if the internal moment exceeds the flexural design strength. The loads associated with the member are doubled and redistributed to the member below, and analysis is repeated. This corresponds to the sequential removal of members when their ultimate moment capacities are exceeded and replacing them with fixed moments equal in magnitude to their ultimate moment capacity, then reanalyzing the remaining structure. At the conclusion of analysis, the extent of damage is quantified, which is similar to the GSA requirements. For removal of a column on the exterior envelope of the building, the local damaged area of the floor directly above or below the removed member must be les the $70 \mathrm{~m}^{2}\left(750 \mathrm{ft}^{2}\right)$ or 15 percent of the floor area, whichever is smaller.

While the linear static analysis is relatively simple, it approximates to the behavior of the actual building performance and may sometimes mask hazardous dynamic effects. The linear static analysis cannot account for the redistribution of forces, nonlinear material properties, and the development of membrane modes of resistance. Thus, this approach, in general, would produce conservative designs.

\subsection{Nonlinear Static Analysis}

In nonlinear static analysis, geometric nonlinearlity resulting from large deformations can be accounted for through the redistribution of loads as a result of the removal of a critical column (Fig. 1), and the structure attempts to reequilibrate to the larger spans through a change in behavior from a flexural response to a membrane response. In analysis the loads are applied in steps starting at zero to the total load level as defined by Eq. 2. At least 10 steps are recommended by UFC [UFC 2004]. At the end of the analysis, the predicted forces, moments, shears and deformations must be checked against the acceptance criteria (Table 1).

If none of the structural members and connections violates the acceptance criteria, the analysis is complete and satisfactory resistance to progressive collapse has been demonstrated. If one or more members violate the acceptance criteria, the analysis is repeated with a modified structural model by removing failed structural members, and the load is applied incrementally again. This incremental/iterative process continues until the structural model stabilizes. If the collapse process cannot be stopped, then the structure must be re-designed and re-analyzed. If the structural model does stabilize, then the performance criteria of the damaged area must be checked.

Nonlinear analyses depend on an accurate representation of material behavior to represent inelastic response. Of particular importance is the actual behavior of the joints as they undergo inelastic deformation. Nonlinear springs representing the behavior of the joints are required.

Nonlinear analyses require reasonably detailed finite element models to represent nonlinear behavior of the structure, and are time consuming because the need for step-by-step 
increases of vertical loads until maximum loads are attained or until the structure collapses.

\section{Conclusion}

The potential progressive collapse analysis entails evaluating a structure for its vulnerability to the development of a partial or a total collapse of the structure initiated by an event that causes local damage. At the present time, there are no accepted simple analytical tools that design professionals could use to analyze progressive collapse potential of low- and mid-rise buildings. Although there are high-performance finite element analysis tools are available, they are not widely used due mainly to the lack of familiarity with the structural behavior associated with progressive collapse, and the lack of sufficient skills to develop complex structural models and interpret computational results.

Until more experimental data become available to represent inelastic response of structural elements, it would be practical to use simpler analysis methods based on linear elastic static procedures, as their results could be validated by simpler methods such as hand calculations. Thus, simpler analysis methods are preferred from a computational point of view.

When the results of linear elastic static procedures violate acceptance criteria, nonlinear static procedures should be attempted to account for the redistribution of the loads of failed members and the development of membrane action.

\section{REFERENCES}

ASCE 7-02 (2002), "Minimum Design Loads for Buildings and Other Structures, 2002 edition," American Society of Civil Engineers, Reston, VA

GSA (2003), "Progressive Collapse Analysis and Design Guidelines for New Federal Office Buildings and Major Modernization Projects, General Services Administration, Washington, D.C.
ISC (2001), "ISC Security Criteria for New Federal Office Buildings and Major Modernization Projects," The Inter Agency Committee

UFC (2004), "Unified Facility Criteria-Draft Design of Buildings to Resist Progressive Collapse," Department of Defense 
Table 1. Acceptance Criteria and Subsequent Action

\begin{tabular}{|l|l|l|}
\hline $\begin{array}{c}\text { Structural } \\
\text { Behavior }\end{array}$ & \multicolumn{1}{|c|}{ Acceptance Criteria } & \multicolumn{1}{c|}{ Subsequent Action } \\
\hline Flexure & Flexural design strength & $\begin{array}{l}\text { For ductile members, insert hinge and } \\
\text { apply a constant moment on both sides of } \\
\text { the hinge. }\end{array}$ \\
\hline $\begin{array}{l}\text { Combine axial } \\
\text { and flexure }\end{array}$ & Interaction equation & $\begin{array}{l}\text { Remove failed members and redistribute } \\
\text { the failed member loads. }\end{array}$ \\
\hline Shear & Shear design strength & $\begin{array}{l}\text { Remove failed members and redistribute } \\
\text { the failed member loads. }\end{array}$ \\
\hline Deformation & $\begin{array}{l}\text { Limits defined for each } \\
\text { material (FEMA 356) }\end{array}$ & $\begin{array}{l}\text { Remove failed members and redistribute } \\
\text { the failed member loads. }\end{array}$ \\
\hline
\end{tabular}

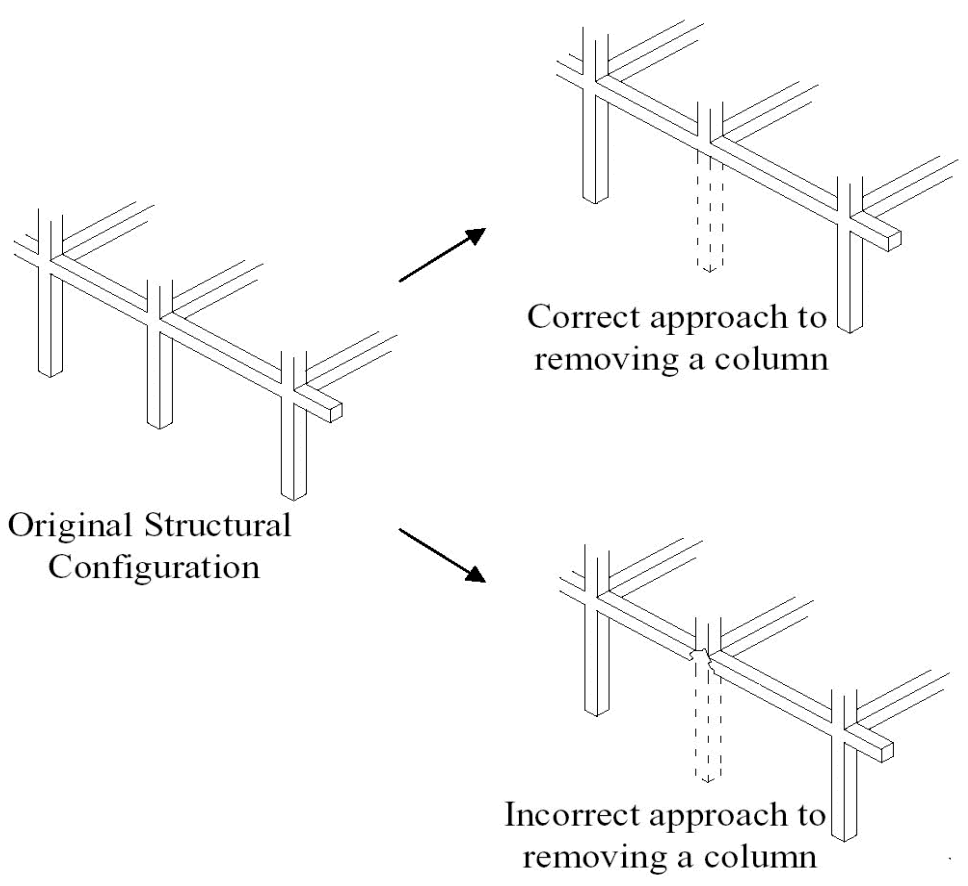

